\title{
Measuring Clients' Perception of Functional Limitations Using the Perceived Functioning \& Health Questionnaire
}

\author{
J. M. H. Schellekens • F. I. Abma • H. P. G. Mulders • \\ S. Brouwer
}

Published online: 30 March 2010

(C) The Author(s) 2010. This article is published with open access at Springerlink.com

\begin{abstract}
Background The Perceived Functioning \& Health (PFH) questionnaire was developed to collect, in a standardized manner, which work activities are limited due to health conditions according to the perception of the client. In this study the questionnaire's reliability and validity are investigated. Methods The PFH questionnaire is comprised of 147 questions, distributed over 33 scales, pertaining to the client's psychosocial and physical work limitations. The PFH data of 800 respondents were analyzed: 254 healthy employees, 408 workers on sick leave and 138 recipients of a disability pension. Internal consistency (Cronbach's $\alpha$ ) for the scales was established. The test-retest reliability was examined for the data of 52 recipients of a disability pension who filled out the PFH twice within an interval of 1 month. Validation was established by taking the nature of the limitations as a criterion: mental limitations, physical limitations or a mix of both. To this end, the respondents were divided into groups distinguished on the basis of self-classification, as well as classification on the basis of disease codes given by insurance and occupational health physicians: a "healthy" group, subjects with only physical ("physical" group) or mental
\end{abstract}

J. M. H. Schellekens $(\varangle)$ · F. I. Abma

Department of Experimental and Work Psychology, University

of Groningen, Gr. Kruisstraat 2-1, 9712 TS Groningen,

The Netherlands

e-mail: j.m.h.schellekens@rug.nl

F. I. Abma $\cdot$ S. Brouwer

Department of Health Sciences, Social Medicine, University

Medical Center Groningen, University of Groningen, Groningen,

The Netherlands

H. P. G. Mulders

Dutch Institute for Social Insurance, Knowledge Center,

Amsterdam, The Netherlands limitations ("mental" group) or mixed limitations ("mixed" group). The scale scores of these groups were compared and tested using analyses-of-variance and discriminant analyses. Results The scales were found to have sufficient to good internal consistency (mean Cronbach's- $\alpha=0.79$ ) and testretest reliability (mean correlation $r=0.76$ ). Analyses-ofvariance demonstrated significant differences between the scores of the mental, physical and healthy groups on most of the expected scales. These results were found both in groups defined by self-classification as well as in groups based on disease codes. Moreover, discriminant analyses revealed that the a priori classification of the respondents into three groups (mental, physical, healthy) for more than $75 \%$ of them corresponded with the classification on the basis of scale scores obtained from the questionnaire. Furthermore, limitations due to specific types of complaints (low back pain, fatigue, concentration problems) or diagnosed disorders (musculoskeletal disorders, reactive disorders, endogenous disorders) were clearly reflected in the scores of the related scales of the PFH. Conclusion The psychometric properties of the $\mathrm{PFH}$ with respect to reliability and validity were satisfactory. The PFH would appear to be an appropriate instrument for systematically measuring functional limitations in subjects on sick leave and in those receiving disability pensions, and could be used as a starting point in a disability claim procedure.

Keywords Work limitations · Disability - Validity · Reliability · Questionnaire

\section{Introduction}

In many countries it is the statutory responsibility of occupational health and insurance physicians to assess 
subjects' functional limitations within the context of return to work and disability claim procedures. To map the abilities and limitations of the client, insurance and occupational health physicians make use of an insurance-medical research consisting, among other things, of an assessment interview [1-3]. Several studies have noted that the assessment to a large extent is based on the information reported by the insured persons themselves $[1,4,5]$. In a qualitative study, 94 insurance physicians were interviewed about the sources of information they used to assess clients' work limitations [2]. It turned out that less than $20 \%$ of the determined limitations were based on the observation and knowledge of the insurance physician. The remaining limitations were introduced by the insured persons themselves. More than $30 \%$ of these remaining limitations were obtained after in-depth questioning by the insurance physician or purely by chance [2]. Therefore, insured persons themselves would seem to be the most important source of relevant knowledge concerning their own abilities and limitations.

In support of the interview, an instrument was sought with which clients could report their perceived work limitations themselves. That instrument could be seen as a type of "Injury Claim Form" in which the client could set forth the problems which he/she experienced with his/her work functioning. It could be used as a starting point in the process of screening and classification in work disability/ ability assessment and in medical insurance claims. In a subsequent assessment step, other more specific instruments or methods could be used to confirm the initial assessment results and to establish the causes and underlying mechanisms of the limitation.

Several authors have pointed out that work disability needs to be understood as a multi-factorial phenomenon, influenced by physical and psychosocial factors [6-8], which involves assessment within several domains of functioning and disability. Different questionnaires are available to assess limitations in work functioning [9-14]. However, most of them are specific questionnaires, related to a specific diagnosis, or related to another context (sport, rehabilitation), and they deal mostly with physical aspects only. Up until now there has been, to the best of our knowledge, no questionnaire available which contains items concerning a client's work limitations in terms of both the physical and psychosocial domains of work disability.

The PFH questionnaire is a self-report list that has been developed to gather, in a standardized and systematic way, a client's perceived limitations in both the physical and psychosocial domains of functioning due to limitations or injury [15]. The content of the PFH is derived from the items of the Dutch "Functional Ability List" (FAL) [3]. The FAL is a checklist for occupational health and insurance physicians which is used as the standard method in the Netherlands for assessing a client's physical and psychosocial work limitations. It is part of the "Claim Beoordelings- en Borgingssysteem" (CBBS), the Dutch equivalent of the dictionary of occupational titles (DOT) [16]. The FAL consists of 68 items grouped into six headings: (1) Personal functioning; (2) Social functioning; (3) Adjusting to physical environment; (4) Dynamic movement; (5) Static postures; and (6) Working hours. The results of this assessment are included in a report in which the abilities and limitations of work performance are described and evaluated. The physical items of the PFH are based on the headings "Dynamic movement" and "Static postures"; the psychosocial items are based on the headings "Personal functioning" and "Social functioning." The item "Other limitations," belonging under the headings of personal and social functioning, has been defined consistently within the framework of the current state of knowledge regarding labor-related risk factors related to actual work load versus functional capacity, in so far as these factors are related to the psychosocial domain [1721]. Because of the usability of the PFH for physicians in their daily assessment work, the scales and the grouping of the scales are kept parallel to the FAL as much as possible.

The aim of the present study is to investigate the reliability and validity of the PFH. With regard to reliability, the test-retest reliability and internal consistency of the items were both established. No gold standard exists for validation of perceived limitations in functioning, however. Therefore, for validation purposes an "a priori" classification of the respondents took place on the basis of their own statements (self-classification). Four groups were distinguished: a working non-sick group of subjects without limitations (healthy group); subjects with only physical (physical group) or only mental (mental group) limitations; or both physical and mental limitations (mixed group). Initially, validation took place by determining the consistency between the self-classification and the scale scores in the PFH self-report. It was expected that clients in the group with physical limitations would receive a high score, especially on the scales that measured physical limitations, while clients with mental complaints would have high scores on the non-physical scales of the questionnaire. In addition, the association between specific limitations and the scores on the related scales of the questionnaire were evaluated. For example, attention and memory problems should be reflected in higher limitation scores on the attention and memory scales of the PFH.

Although a good relationship between perceived limitations and scale scores was to be expected, investigating the consistency between self-classification and the usual classification based on disease codes might prove interesting. These disease codes are assigned by insurance 
physicians (recipients of a disability pension) and occupational health physicians (sick-listed workers) according to the classification of diseases (CAS) [22] which is based on the ICD-10 [23]. On the basis of disease codes, clients could also be classified into groups with physical limitations, non-physical limitations, and both physical and nonphysical limitations. Moreover, the relationship between some specific disease codes and their related scale scores could be evaluated.

\section{Methods}

\section{Respondents}

The questionnaire was completed on a voluntary basis by 807 respondents. They were recruited by Occupational Health Services, the Dutch Institute for Social Insurance, as well as through advertisements in regional newspapers and on the Internet. Three categories of respondents were distinguished: employed non-sick persons $(n=254)$; persons on sick leave $(n=408)$; and recipients of a disability pension $(n=138)$. The data for seven respondents were excluded because of missing data. In Table 1a information about the characteristics of the respondents are presented.

\section{Questionnaire}

All respondents received a questionnaire which consisted of questions about demographic factors (age, gender), questions about work status and type of health condition(s) and the PFH questionnaire to measure perceived limitations in functioning. The PFH consists of 147 items, distributed over 33 scales and listed under the headings "Cognitive \& personal functioning," "Social functioning" and "Physical functioning" (Table 2 Columns 1-2). Some examples of the items are: "Do you almost immediately forget what somebody has just told you?" (item from the scale limitations in "Memory," heading "Cognitive functioning"); "Do you feel afterwards that you have underestimated your own abilities?" (item from limitations in "Underestimating one's own capacity," heading Personal functioning); "Do others have to tell you what still needs to be done?" (item of limitations in "Acting autonomously," heading "Personal functioning"); "Do you take the initiative to meet new people?" (item of limitations in "Contact with others," heading "Social functioning"); "Are you limited in your daily life when using your hands or fingers?" (item of limitations in "Physical Functioning: using hand/arms," heading "Physical functioning"). Each item has four response alternatives: $0=$ "(almost) never," $1=$ "sometimes," $2=$ "often" and $3=$ "(almost) always." If necessary, item scores were converted so that higher values always represented more limitations. The scores were averaged and the mean was transferred to $0-100$ scores.

\section{Analysis Procedure}

\section{Reliability}

The initial selection and grouping of items in each scale was based on content considerations that had to be
Table 1 Characteristics of the subjects in the original groups (a), and groups classified on the basis of self-classification (b) and disease code (c)

\begin{tabular}{lccc}
\hline & $N$ & $\%$ men & Mean (SD) age (in years) \\
\hline a. Original groups & 254 & 50.8 & $37.3(10.5)$ \\
Workers & 546 & 39.7 & $40.8(10.5)$ \\
Non-workers & 408 & 41.2 & $42.0(10.4)$ \\
$\quad$ Persons on sick leave & 138 & 41.5 & $39.7(9.9)$ \\
$\quad$ Persons with disability pension & 800 & 43.3 & $39.7(10.6)$ \\
Total $N$ & 254 & 50.8 & \\
b. Classification on the basis of self-classification & 40.8 & $47.3(10.5)$ \\
Healthy group & 287 & 38.8 & $40.1(9.7)$ \\
Physical group & 103 & 38.5 & $40.8(10.5)$ \\
Mental group & 156 & 43.3 & $39.7(10.6)$ \\
Mixed group & 800 & & \\
Total $N$ & & & \\
c. Classification on the basis of disease code & 254 & 50.8 & $43.3(10.5)$ \\
Healthy group & 178 & 44.9 & $40.6(10.5)$ \\
Physical group & 108 & 41.1 & $41.5(9.9)$ \\
Mental group & 22 & 63.6 & $39.9(10.7)$ \\
Mixed group & 562 & 47.6 & \\
Total $N$ & & & \\
\hline
\end{tabular}


Table 2 Scales of the PFH (description and number of items), Cronbach's alpha $(\alpha)$ and test-retest results (Pearson correlations $(r)$ and Paired $t$-test $(P$-values $))$

\begin{tabular}{|c|c|c|c|c|c|}
\hline & $\begin{array}{l}\text { Scales } \\
1\end{array}$ & $\begin{array}{l}\text { No of items } \\
\text { (total } n=147 \text { ) } \\
2\end{array}$ & $\begin{array}{l}\text { Cronbachs } \alpha \\
(n=800) \\
3\end{array}$ & $\begin{array}{l}\text { Pearson }(r)^{*} \\
(n=52)^{\mathrm{a}} \\
4\end{array}$ & $\begin{array}{l}T \text {-test }(P) \\
(n=52)^{\mathrm{a}} \\
5\end{array}$ \\
\hline & Cognitive functioning & & & & \\
\hline 1 & Memory & 4 & 0.80 & 0.87 & 0.83 \\
\hline 2 & Selective attention & 4 & 0.78 & 0.82 & 0.29 \\
\hline 3 & Sustained attention & 4 & 0.78 & 0.80 & 0.84 \\
\hline 4 & Divided attention & 4 & 0.74 & 0.80 & 0.89 \\
\hline \multirow[t]{2}{*}{5} & Thinking & 4 & 0.81 & 0.77 & 0.15 \\
\hline & Personal functioning & & & & \\
\hline 6 & Underestimating one's own capacity & 4 & 0.67 & 0.73 & 0.94 \\
\hline 7 & Overestimating one's own capacity & 4 & 0.61 & 0.75 & 0.55 \\
\hline 8 & Acting according to plan & 4 & 0.68 & 0.73 & 0.66 \\
\hline 9 & Planning in advance & 3 & 0.70 & 0.74 & 0.56 \\
\hline 10 & Acting autonomously & 4 & 0.74 & 0.63 & 0.47 \\
\hline 11 & Acting rate of speed & 4 & 0.87 & 0.79 & 0.33 \\
\hline 12 & Fatigue $^{\mathrm{b}}$ & 4 & 0.86 & - & - \\
\hline 13 & Acting under pressure and stress & 4 & 0.87 & 0.79 & 0.35 \\
\hline 14 & Adaptability: work & 4 & 0.83 & 0.75 & 0.93 \\
\hline 15 & Adaptability: people & 3 & 0.78 & 0.74 & 0.40 \\
\hline 16 & Being assertive & 4 & 0.79 & 0.76 & 0.48 \\
\hline 17 & Motivation & 4 & 0.83 & 0.77 & 0.58 \\
\hline \multirow[t]{2}{*}{18} & Anxious and uncertain & 4 & 0.84 & 0.78 & 0.76 \\
\hline & Social functioning & & & & \\
\hline 19 & Informing other subjects & 4 & 0.83 & 0.76 & 0.07 \\
\hline 20 & Dealing with emotional problems of other subjects & 4 & 0.50 & 0.73 & 0.79 \\
\hline 21 & Expressing one's own feelings & 4 & 0.73 & 0.72 & 0.13 \\
\hline 22 & Controlling one's own emotions & 4 & 0.77 & 0.79 & 0.59 \\
\hline 23 & Dealing with inner conflicts & 4 & 0.68 & 0.71 & 0.45 \\
\hline 24 & Dealing with conflict situations & 4 & 0.68 & 0.72 & 0.72 \\
\hline 25 & Cooperating with others & 4 & 0.80 & 0.73 & 0.06 \\
\hline 26 & Contact with other subjects & 4 & 0.81 & 0.88 & 0.43 \\
\hline 27 & Pleasure & 4 & 0.86 & 0.80 & 0.70 \\
\hline 28 & Dealing with setbacks & 4 & 0.83 & 0.78 & 0.90 \\
\hline \multirow[t]{2}{*}{29} & Social support & 4 & 0.88 & 0.60 & 0.08 \\
\hline & Physical functioning & & & & \\
\hline 30 & Using back/legs & 16 & 0.96 & 0.84 & 0.21 \\
\hline 31 & Using hands/arms & 7 & 0.93 & 0.80 & 0.01 \\
\hline 32 & Using neck & 4 & 0.93 & 0.77 & 0.06 \\
\hline 33 & Using senses & 6 & 0.82 & 0.82 & 0.60 \\
\hline
\end{tabular}

${ }^{a}$ In test-retest reliability study only data available of the disabled group

b This scale has been added to the questionnaire after conducting the test-retest study

* All results with $P \leq 0.001$

confirmed by factor analysis. After factor analysis, a Cronbach's alpha $(\alpha)$ was calculated as a measurement of consistency or item reliability [24]. For 52 recipients of a disability pension, the test-retest reliability (Pearson
Correlation) was calculated after they had completed the PFH twice within an interval of 1 month. A Cronbach's $\alpha$ or a test-retest reliability $\geq 0.80$ indicated good reliability, $\geq 0.60$ indicated sufficient reliability $[25,26]$. Paired $t$-test 
analysis was performed to look for significant differences $(P \leq 0.05)$.

\section{Validation}

To determine to what extent the questionnaire was truly measuring what it was intended to measure, the scores of the questionnaire had to be correlated with a criterion [24]. Due to the lack of a hard criterion, groups of respondents were distinguished on the basis of self-classification and on the basis of disease codes. Self-classification was based on the respondent's answer to one question "What type of health complaint currently limits you in your daily life?" The possible answers were: (1) predominantly physical limitations; (2) predominantly non-physical limitations; (3) both physical and non-physical limitations; and (4) no limitations. Classification was also based on disease codes assigned by insurance physicians and occupational health physicians according to the CAS [22]. Four groups were distinguished: (1) working non-sick subjects (healthy group), (2) subjects on sick-leave or receiving disability benefits with physical limitations (physical group), (3) subjects on sick-leave or receiving disability benefits with mental limitations (mental group) and (4) subjects with both physical and mental limitations (mixed group). Due to possible discrepancies between self-classification and classification based on disease codes, the analyses of both sources of information were conducted separately (see Table 1b, c).

In comparison with the healthy group, respondents with physical limitations (physical group) should score higher than the mental and healthy groups on the physical scales of the PFH, while respondents with mental limitations (mental group) should score higher than physical and healthy groups on the non-physical scales, and respondents with both physical and mental limitations (mixed group) should score higher than the healthy group on all PFH scales. To evaluate validity, differences among the four groups (healthy, physical, mental and mixed groups) were tested for significance $(P \leq 0.05)$ with multi- and univariate analyses of variance (MANOVA) [27, 28]. To further examine the established differences, post-hoc analyses (using the Scheffé criterion) were used [28]. The test results were adjusted for age and sex differences between the groups by using age as a covariable and sex as an additional classification variable in the MANOVA.

It was expected that respondents in the mental, physical and mixed groups would show high limitation scores on the related scales of the PFH questionnaire. To illustrate this, a high arbitrary critical score was chosen such that the mean for all the limitation groups should exceed the 80th percentile score of the healthy group. Should limitation scores fall above this 80th percentile values for the healthy group, then one could speak of an abnormally high score, in the statistical sense. The PFH results for the three limitation groups were compared with the 80th percentile values for the healthy group.

Discriminant analysis was performed to demonstrate to what extent the classification on the basis of the scale scores obtained from the questionnaire corresponded with the a priori classification of the respondents into groups (mental, physical, mixed, healthy), and to demonstrate how many scales were minimally needed in order to distinguish these groups (selection of a core set of distinguishing variables).

\section{Results}

\section{Reliability}

All items in each scale appeared to load on one factor or dimension and all scales appeared to have sufficient to good internal consistency (Cronbach's $\alpha$ : mean $=0.79$, $\mathrm{SD}=0.10$, range $=0.61-0.96)$, with the exception of the scale "Dealing with emotional problems of other subjects" (scale 20) $(\alpha=0.50)$ (Table 2 Column 3).

With respect to test-retest reliability, the scale scores of the PFH collected after a month scarcely differed from those of the first measurement. Pearson correlations showed an average of $r=0.76 \quad(\mathrm{SD}=0.06$, range $=$ $0.60-0.88)$ and were all significant $(P<0.001)$ (Table 2 Column 4). From paired $t$-tests, no significant $(P>0.05)$ difference existed between test and re-test, with the exception of "Physical functioning: using hands/arms" (Scale 31$)(P=0.01)$ (Table 2 Column 5).

\section{Validity}

\section{Validity Based on Self-Classification}

Limitation Groups The 800 respondents were divided into four groups based on self-classification: a healthy group $(n=254)$, a physical group $(n=287)$, a mental group $(n=103)$ and a mixed group $(n=156)$. The healthy group ( $n=254$ ) was used as the reference group.

In Table 3 (Column 5), it can be seen that the groups scored significantly differently on all the scales (MANOVA: $P \leq 0.001$ and ANOVA: $P \leq 0.001)$ with the exception of the scale "Planning in Advance" (Scale 9). Post-hoc analyses (Table 3 Column 6) revealed the origin of these differences among the groups. In comparison with the healthy group, subjects with physical limitations scored higher on the physical scales and on scales that were related to the so-called "energetic state" [indicated by the scales: "Sustained Attention" (Scale 3), "Acting Rate of 
Table 3 Means and standard deviations (SD) per scale and self-classification group

\begin{tabular}{|c|c|c|c|c|c|c|c|c|c|c|c|c|c|c|c|c|}
\hline \multirow{2}{*}{\multicolumn{2}{|c|}{$\begin{array}{l}\text { Self-classification } \\
\text { Scales }\end{array}$}} & \multirow{2}{*}{\multicolumn{2}{|c|}{$\frac{\text { Healthy }}{1}$}} & \multirow{2}{*}{\multicolumn{2}{|c|}{$\frac{\text { Physical }}{2}$}} & \multirow{2}{*}{\multicolumn{2}{|c|}{$\frac{\text { Mental }}{3}$}} & \multirow{2}{*}{\multicolumn{2}{|c|}{$\frac{\text { Mixed }}{4}$}} & \multirow{3}{*}{$\begin{array}{l}\text { GLM } \\
5 \\
P<\end{array}$} & \multicolumn{6}{|c|}{ Post-hoc analyses 6} \\
\hline & & & & & & & & & & & \multirow{2}{*}{$\begin{array}{l}\mathrm{a} \\
\mathrm{Ph}- \\
\mathrm{He}\end{array}$} & \multirow{2}{*}{$\begin{array}{l}\mathrm{b} \\
\mathrm{Me}- \\
\mathrm{He}\end{array}$} & \multirow{2}{*}{$\begin{array}{l}\mathrm{c} \\
\mathrm{Mi}- \\
\mathrm{He}\end{array}$} & \multirow{2}{*}{$\begin{array}{l}\mathrm{d} \\
\mathrm{Ph}- \\
\mathrm{Me}\end{array}$} & \multirow{2}{*}{$\begin{array}{l}\mathrm{e} \\
\mathrm{Ph}- \\
\mathrm{Mi}\end{array}$} & \multirow{2}{*}{$\begin{array}{l}\mathrm{f} \\
\mathrm{Me}- \\
\mathrm{Mi}\end{array}$} \\
\hline & & Mean & SD & Mean & SD & Mean & SD & Mean & $\mathrm{SD}$ & & & & & & & \\
\hline & Cognitive functioning & & & & & & & & & & & & & & & \\
\hline 1 & Memory & 20.5 & 9.8 & 25.6 & 17.7 & 37.9 & 19.0 & 41.3 & 19.4 & 0.00 & 0.96 & $0.01 \mathrm{c}$ & $0.01 \mathrm{c}$ & 0.01 & 0.01 & 1.00 \\
\hline 2 & Selective attention & 32.6 & 17.0 & 37.0 & 21.2 & 50.5 & 20.3 & 53.4 & 21.1 & 0.00 & 1.00 & $0.01 \mathrm{c}$ & $0.01 \mathrm{c}$ & 0.01 & 0.01 & 0.41 \\
\hline 3 & Sustained attention & 15.2 & 16.5 & 24.1 & 23.2 & 34.5 & 25.4 & 39.5 & 25.6 & 0.00 & 0.01 & $0.01 \mathrm{c}$ & $0.01 \mathrm{c}$ & 0.01 & 0.01 & 1.00 \\
\hline 4 & Divided attention & 20.4 & 14.0 & 26.6 & 20.5 & 33.8 & 21.4 & 36.9 & 22.6 & 0.00 & 1.00 & $0.01 \mathrm{c}$ & $0.01 \mathrm{c}$ & 0.01 & 0.01 & 0.95 \\
\hline \multirow[t]{2}{*}{5} & Thinking & 19.3 & 13.8 & 28.1 & 19.4 & 41.4 & 19.8 & 45.2 & 22.1 & 0.00 & 0.01 & $0.01 \mathrm{c}$ & $0.01 \mathrm{c}$ & 0.01 & 0.01 & 1.00 \\
\hline & Personal functioning & & & & & & & & & & & & & & & \\
\hline 6 & Underestimating one's own capacity & 28.6 & 14.3 & 27.8 & 16.4 & 42.0 & 20.4 & 40.8 & 17.9 & 0.00 & 0.37 & $0.01 \mathrm{c}$ & $0.01 \mathrm{c}$ & 0.01 & 0.01 & 1.00 \\
\hline 7 & Overestimating one's own capacity & 19.6 & 12.2 & 22.5 & 13.3 & 27.0 & 14.3 & 31.0 & 15.5 & 0.00 & 1.00 & 0.04 & $0.01 \mathrm{c}$ & 0.16 & 0.01 & 1.00 \\
\hline 8 & Acting according to plan & 25.2 & 14.7 & 28.8 & 17.4 & 36.6 & 20.5 & 38.3 & 19.3 & 0.00 & 1.00 & 0.02 & $0.01 \mathrm{c}$ & 0.03 & 0.01 & 0.01 \\
\hline 9 & Planning in advance & 27.9 & 20.6 & 31.0 & 22.7 & 32.1 & 24.7 & 31.9 & 22.6 & 0.15 & 0.89 & 0.63 & 0.30 & 1.00 & 1.00 & 1.00 \\
\hline 10 & Acting autonomously & 17.8 & 12.3 & 17.5 & 14.3 & 24.5 & 17.6 & 24.0 & 16.6 & 0.01 & 0.66 & 0.29 & 0.18 & 0.01 & 0.01 & 1.00 \\
\hline 11 & Acting rate of speed & 12.5 & 15.0 & 29.2 & 28.2 & 27.4 & 26.0 & 38.7 & 30.1 & 0.00 & $0.01 \mathrm{c}$ & $0.01 \mathrm{c}$ & $0.01 \mathrm{c}$ & 1.00 & 0.12 & 0.66 \\
\hline 12 & Fatigue & 21.6 & 17.8 & 33.4 & 23.5 & 49.9 & 25.1 & 49.3 & 24.9 & 0.00 & 0.01 & $0.01 \mathrm{c}$ & $0.01 \mathrm{c}$ & 0.01 & 0.01 & 1.00 \\
\hline 13 & Acting under pressure \& stress & 28.1 & 19.0 & 36.3 & 21.7 & 52.0 & 21.7 & 53.0 & 24.4 & 0.00 & 0.03 & $0.01 \mathrm{c}$ & $0.01 \mathrm{c}$ & 0.01 & 0.01 & 1.00 \\
\hline 14 & Adaptability: work & 25.1 & 16.7 & 30.5 & 19.0 & 43.2 & 21.5 & 45.1 & 20.0 & 0.00 & 0.91 & $0.01 \mathrm{c}$ & $0.01 \mathrm{c}$ & 0.01 & 0.01 & 1.00 \\
\hline 15 & Adaptability: people & 31.4 & 19.8 & 28.9 & 19.2 & 32.7 & 20.9 & 41.9 & 25.5 & 0.00 & 0.14 & 1.00 & 0.01 & 0.01 & 0.01 & 0.01 \\
\hline 16 & Being assertive & 30.2 & 17.8 & 32.5 & 19.7 & 51.3 & 19.7 & 47.2 & 22.1 & 0.00 & 1.00 & $0.01 \mathrm{c}$ & $0.01 \mathrm{c}$ & 0.01 & 0.01 & 1.00 \\
\hline 17 & Motivation & 19.8 & 14.6 & 21.5 & 16.6 & 31.0 & 22.3 & 35.0 & 20.6 & 0.00 & 1.00 & 0.01 & $0.01 \mathrm{c}$ & 0.01 & 0.01 & 1.00 \\
\hline \multirow[t]{2}{*}{18} & Anxious and uncertain & 22.7 & 15.7 & 24.4 & 17.9 & 46.0 & 22.5 & 43.2 & 22.1 & 0.00 & 1.00 & $0.01 \mathrm{c}$ & $0.01 \mathrm{c}$ & 0.01 & 0.01 & 1.00 \\
\hline & Social functioning & & & & & & & & & & & & & & & \\
\hline 19 & Informing other subjects & 22.1 & 15.7 & 25.1 & 17.5 & 33.4 & 19.7 & 31.4 & 19.7 & 0.00 & 1.00 & 0.01 & 0.01 & 0.01 & 0.01 & 1.00 \\
\hline 20 & $\begin{array}{l}\text { Dealing with emotional problems of } \\
\text { other subjects }\end{array}$ & 29.3 & 13.9 & 29.6 & 14.9 & 39.0 & 15.9 & 38.8 & 16.2 & 0.00 & 1.00 & 0.01 & 0.01 & 0.01 & 0.01 & 0.53 \\
\hline 21 & Expressing one's own feelings & 29.5 & 16.6 & 33.9 & 16.9 & 46.6 & 18.5 & 45.5 & 20.8 & 0.00 & 0.17 & $0.01 \mathrm{c}$ & $0.01 \mathrm{c}$ & 0.01 & 0.01 & 1.00 \\
\hline 22 & Controlling one's own emotions & 25.8 & 16.1 & 29.2 & 17.2 & 44.7 & 20.7 & 47.7 & 18.9 & 0.00 & 1.00 & $0.01 \mathrm{c}$ & $0.01 \mathrm{c}$ & 0.01 & 0.01 & 1.00 \\
\hline 23 & Dealing with inner conflicts & 47.0 & 19.1 & 47.3 & 18.7 & 57.5 & 20.7 & 59.9 & 19.4 & 0.00 & 1.00 & 0.01 & 0.01 & 0.01 & 0.01 & 1.00 \\
\hline 24 & Dealing with conflict situations & 40.1 & 18.5 & 43.8 & 18.1 & 47.3 & 19.4 & 45.4 & 19.0 & 0.00 & 0.91 & 0.02 & 0.02 & 0.03 & 0.30 & 1.00 \\
\hline 25 & Cooperating with others & 17.5 & 15.6 & 14.6 & 15.5 & 19.2 & 16.7 & 23.2 & 18.2 & 0.00 & 0.06 & 1.00 & 0.13 & 0.05 & 0.01 & 0.92 \\
\hline 26 & Contact with other subjects & 29.8 & 21.2 & 33.7 & 21.1 & 44.3 & 25.4 & 48.6 & 26.1 & 0.00 & 1.00 & 0.01 & $0.01 \mathrm{c}$ & 0.01 & 0.01 & 1.00 \\
\hline 27 & Pleasure & 16.8 & 15.2 & 22.7 & 18.4 & 40.1 & 24.0 & 36.1 & 22.7 & 0.00 & 1.00 & $0.01 \mathrm{c}$ & $0.01 \mathrm{c}$ & 0.01 & 0.01 & 1.00 \\
\hline 28 & Dealing with setbacks & 27.4 & 16.4 & 31.4 & 18.4 & 45.7 & 18.7 & 47.3 & 20.2 & 0.00 & 0.41 & $0.01 \mathrm{c}$ & $0.01 \mathrm{c}$ & 0.01 & 0.01 & 1.00 \\
\hline \multirow[t]{2}{*}{29} & Social support & 22.1 & 21.2 & 23.0 & 22.9 & 30.9 & 22.8 & 37.4 & 25.1 & 0.00 & 1.00 & 0.03 & 0.01 & 0.01 & 0.01 & 1.00 \\
\hline & Physical functioning & & & & & & & & & & & & & & & \\
\hline 30 & Using back/legs & 5.9 & 9.1 & 37.3 & 25.6 & 8.7 & 12.5 & 34.2 & 25.4 & 0.00 & $0.01 \mathrm{c}$ & 1.00 & $0.01 \mathrm{c}$ & 0.01 & 0.01 & 0.01 \\
\hline 31 & Using hands/arms & 4.5 & 9.1 & 29.7 & 26.8 & 8.0 & 11.3 & 30.5 & 26.8 & 0.00 & $0.01 \mathrm{c}$ & 1.00 & $0.01 \mathrm{c}$ & 0.01 & 0.48 & 0.01 \\
\hline 32 & Using neck & 3.9 & 10.3 & 23.4 & 27.2 & 7.3 & 16.5 & 24.9 & 25.6 & 0.00 & $0.01 \mathrm{c}$ & 1.00 & $0.01 \mathrm{c}$ & 0.01 & 1.00 & 0.01 \\
\hline 33 & Using senses & 5.0 & 10.1 & 13.5 & 17.5 & 8.7 & 11.1 & 20.0 & 19.5 & 0.00 & 0.01 & 1.00 & $0.01 \mathrm{c}$ & 0.67 & 0.01 & 0.01 \\
\hline
\end{tabular}

He healthy, $P h$ physical, $M e$ mental, $M i$ mixed groups

$P \leq$ (column 5) based on ANOVA with correction for age and sex; $P \leq$ (column 6$)$ based on Scheffé criterion; c $=$ exceeding the 80th percentile of the healthy group

Speed" (Scale 11), "Fatigue" (Scale 12) and "Acting under Pressure and Stress" (Scale 13)] (see Fig. 1 and Table 3 Column 6a). Subjects with mental limitations scored significantly higher on all scales except for the non- physical scales of the PFH (scales 30-33) and the scales "Planning in Advance" (Scale 9), "Acting Autonomously" (Scale 10), "Adaptability: People" (Scale 15) and "Cooperating with Others" (Scale 25) (see Fig. 1 and 


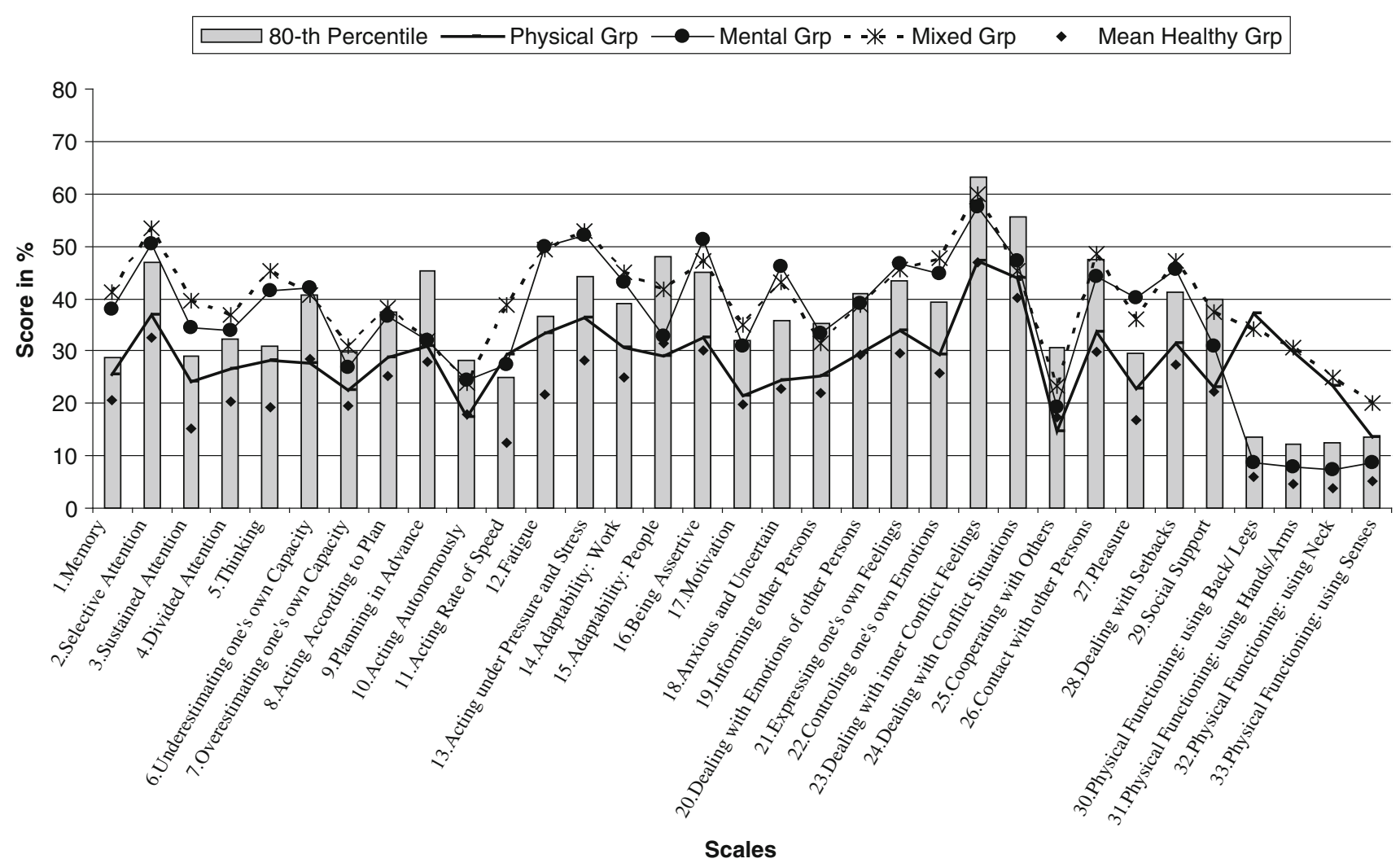

Fig. 1 Mean scale scores of healthy, physical, mental and mixed groups formed on the basis of self-classification. Per scale the 80th percentile value (bars) of the healthy group

Table 3 Column 6b). The mixed group scored significantly higher on all scales compared with the healthy group except for scale "Planning in Advance" (Scale 9), "Acting Autonomously" (Scale 10) and "Cooperating with Others" (Scale 25) (see Fig. 1 and Table 3 Column 6c).

Table 3 (Columns 6d-f) and Fig. 1 show the differences between the physical, mental and mixed groups. In comparison with the physical group, the mental group scored significantly higher on almost all of the non-physical scales, and significantly lower on the physical scales, except for "Physical Functioning: Using Senses" (Scale 33) (Table 3 Column 6d). Comparing the mixed and the physical groups, it appears that the mixed group scored significantly higher on almost all of the non-physical scales, except for "Planning in Advance" (Scale 9), "Acting Rate of Speed" (Scale 11), and "Dealing with Conflict Situations" (Scale 24); significantly higher are the scores of the physical group with regard to the physical scale "Physical Functioning: Using Back/Legs" (Scale 30) and significantly lower with regard to the scale "Physical Functioning: Using Senses" (Scale 33) (Table 3 Column $6 \mathrm{e})$. The mixed and mental groups differed significantly on only two non-physical scales, but the mixed group showed significantly higher scores than the mental group on all physical scales (Table 3 Column 6f).
In general, in comparison with the healthy group, persons with a mental limitation scored higher, particularly on the mental scales of the PFH; persons with a physical limitation did so on the physical scales and on scales that were related to the energetic state. The group with a mix of physical and mental limitations (the mixed group) showed significantly higher scores compared with the healthy group with regard to both the physical and non-physical scale scores. The groups with physical and mental limitations were distinguished on the expected scales. This means that the physical group demonstrated higher physical scale scores than the mental limitation group; in general the mental group showed higher limitation scores on the non-physical scales. The mixed and the mental groups scarcely differed with regard to the non-physical scale scores; the mixed group, however, demonstrated significantly higher limitation scores than the mental group on the physical scales. About the same findings resulted from the comparison between the mixed and physical groups; in general the mixed group showed higher limitation scores on the non-physical scales, but they were only partially distinguished on the physical scales.

Discriminant analysis shows that the a priori classification of the respondents into four groups (the mental, physical and mixed limitations groups and the healthy 
Table 4 Correspondence between a-priori classification (self-classification groups in A and B and disease code groups in C) and classification predicted in discriminant analyses on the basis of PFH scale scores

\begin{tabular}{|c|c|c|c|c|c|c|}
\hline \multicolumn{2}{|c|}{ A. Self-classification groups (\#4) } & \multicolumn{5}{|c|}{ Classification predicted on basis of PFH scale scores } \\
\hline & & Physical group (\%) & Mental group (\%) & Mixed group (\%) & Healthy group (\%) & Total $(\%)$ \\
\hline \multirow[t]{5}{*}{ A-priori classification } & Physical group (\%) & 67 & 3 & 6 & 25 & $100(n=287)$ \\
\hline & Mental group (\%) & 10 & 56 & 8 & 26 & $100(n=103)$ \\
\hline & Mixed group (\%) & 28 & 22 & 30 & 20 & $100(n=156)$ \\
\hline & Healthy group $(\%)$ & 9 & 7 & 1 & 83 & $100(n=254)$ \\
\hline & \multicolumn{5}{|c|}{$65.6 \%$ of a-priori grouped cases correctly classified. } & $N=800$ \\
\hline
\end{tabular}

\begin{tabular}{|c|c|c|c|c|c|}
\hline \multicolumn{2}{|c|}{ B. Self-classification groups (\#3) } & \multicolumn{4}{|c|}{ Classification predicted on basis of PFH scale scores } \\
\hline & & Physical group (\%) & Mental group (\%) & Healthy group (\%) & Total $(\%)$ \\
\hline \multirow[t]{4}{*}{ A-priori classification } & Physical group (\%) & 67 & 5 & 28 & $100(n=287)$ \\
\hline & Mental group (\%) & 11 & 67 & 23 & $100(n=103)$ \\
\hline & Healthy group $(\%)$ & 8 & 5 & 87 & $100(n=254)$ \\
\hline & \multicolumn{4}{|c|}{$75.3 \%$ of a-priori grouped cases correctly classified } & $N=644$ \\
\hline
\end{tabular}

\begin{tabular}{|c|c|c|c|c|c|}
\hline \multicolumn{2}{|c|}{ C. Disease code groups (\#3) } & \multicolumn{4}{|c|}{ Classification predicted on basis of PFH scale scores } \\
\hline & & Physical group (\%) & Mental group (\%) & Healthy group $(\%)$ & Total $(\%)$ \\
\hline \multirow[t]{4}{*}{ A-priori classification } & Physical group (\%) & 67 & 7 & 25 & $100(n=178)$ \\
\hline & Mental group (\%) & 10 & 65 & 25 & $100(n=108)$ \\
\hline & Healthy group $(\%)$ & 4 & 6 & 90 & $100(n=254)$ \\
\hline & \multicolumn{4}{|c|}{$77.6 \%$ of a-priori grouped cases correctly classified. } & $N=540$ \\
\hline
\end{tabular}

group) on the basis of self-classification corresponded to $66 \%$ of the respondents with the classification obtained from the questionnaire on the basis of nine scale scores (Table 4a). This percentage improved to $75.3 \%$ when the a priori distinction was based on only the physical, mental and healthy groups (without the mixed-group) (Table 4b). It proved difficult to differentiate between the mixed and mental groups.

Scores of Self-Classification Groups Compared to 80th Percentiles of the Healthy Group The mean scores of the physical, mental and mixed groups, formed on the basis of self-classification, were compared with the 80th percentiles of the healthy group. Table 3 (Columns 6a-c) shows the groups formed on the basis of self-classification exceeding the 80th percentiles (indicated by "C" in Table 3). Figure 1 illustrates the mean scores of all groups based on self-classification, as well as the 80th percentile values of all 33 scales. As is presented in Table 3 (Column 6a) the mean scores of the physical group exceeded the 80th percentile values of most of the physical scales of the healthy group; thus, the mean score of the physical group lay within the group of $20 \%$ highest limitation scores of the healthy group. The scores of the physical group did not exceed the 80th percentile values of the non-physical scales with exception of the scale "Acting Rate of Speed" (Scale 11). The scores of the mental group exceeded the 80th percentile values of 16 non-physical scales of the healthy group. They did not exceed the 80th percentile values of the physical scales (Table 3 Column 6b). The scores of the mixed group exceeded the 80th percentile values on 24 of the 33 scales, both physical and non-physical (Table 3 Column 6c).

Representation of Self-Expressed Limitations in the Questionnaire Scores To examine whether types of limitations are clearly reflected in the scores of the related scales, three groups of subjects were composed on the basis of their specific limitations and their PFH scores were compared to the 80th percentile value: concentration problems $(n=52)$, fatigue $(n=75)$ and back complaints $(n=106)$ (Fig. 2). The scores of these groups all exceeded the 80th percentile value on those scales which were related to their type of limitations: the group with concentration problems scored the highest on the scales about memory and attention (Scales 1-4), the fatigue group on the scale about fatigue (Scale 12) and the back complaints group on the scale "Physical Functioning: Using Back/Legs" (Scale 30).

\section{Validity Based on Disease Codes}

Limitation Groups For the comparison between groups distinguished on the basis of their disease code, the insurance or occupational health physicians assigned a 


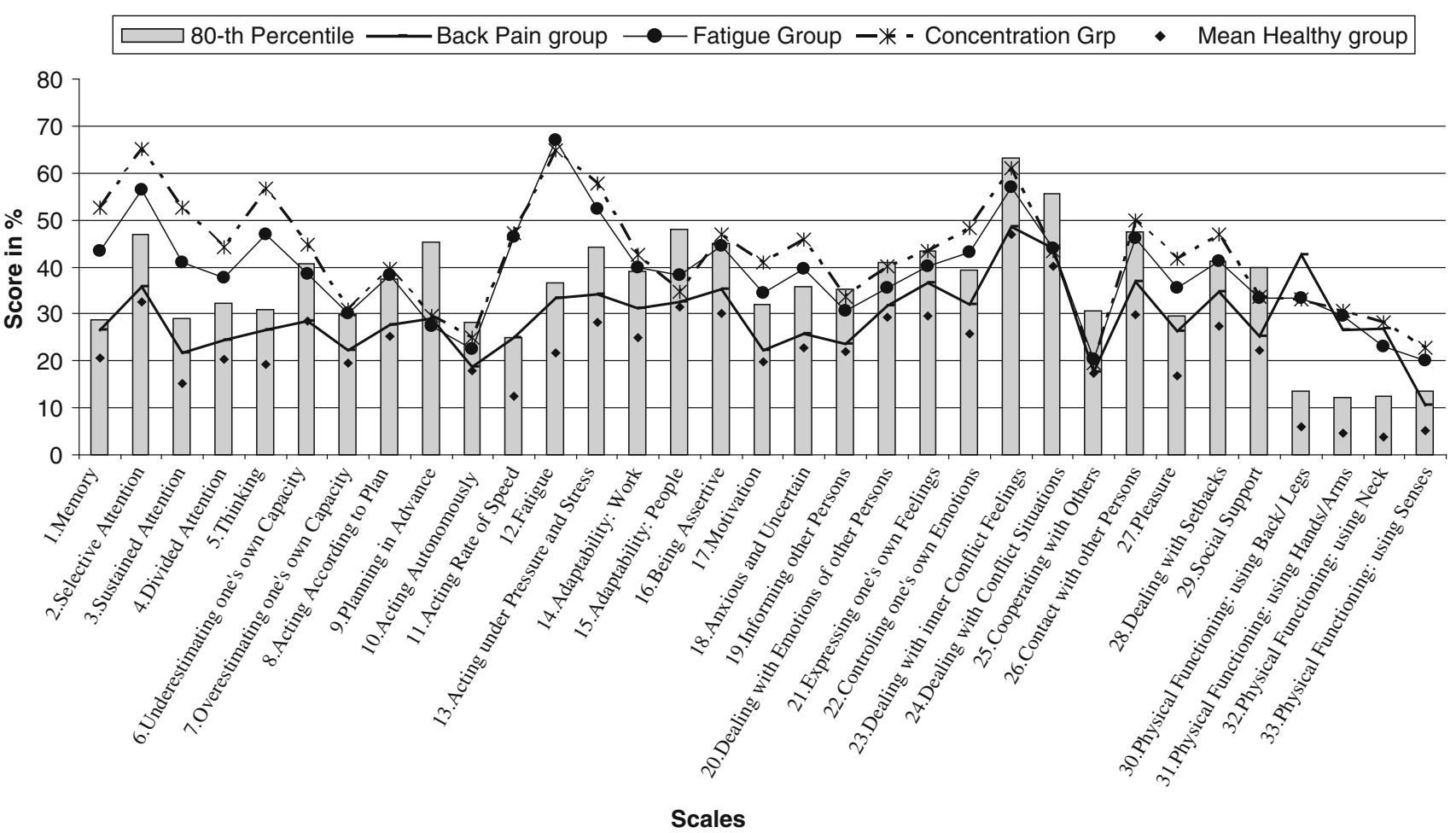

Fig. 2 Mean scale scores of healthy group contrasted with groups with Fatigue, Back and Concentration complaints formed on basis of selfclassification. Per scale the 80th percentile value (bars) of the healthy group

diagnostic label to the respondents in terms of one or two disease codes. Only these respondents were divided into the physical group $(n=178)$, mental group $(n=108)$ or mixed group $(n=22)$; the other respondents were excluded from the analyses. The healthy group $(n=254)$ was again used as a reference group. Due to the small number of subjects in the mixed group, this group was excluded from further analyses.

Table 5 (Columns 1-3) and Fig. 3 show the differences between the disease code groups and the healthy group. The three groups, the physical, mental and healthy groups, differed from each other on all scales (MANOVA: $P \leq 0.001$ and ANOVA: $P \leq 0.003$; Table 5 Column 4) except for the scale "Planning in Advance" (Scale 9) $(P=0.09)$. Post-hoc analyses demonstrated that in comparison with the healthy group, subjects with physical limitations scored significantly higher on the physical scales and on the scales "Thinking" (scale 5), "Acting Rate of Speed" (Scale 11), "Fatigue" (Scale 12), "Acting under Pressure and Stress" (Scale 13), "Expressing one's own Feelings" (Scale 21) and "Dealing with Conflict Situations" (Scale 24) and significantly lower on the scales "Underestimating one's own Capacity" (Scale 6), "Adaptability: People" (Scale 15) and "Cooperating with Others" (Scale 25) (Table 5 Column 5a). Comparing the healthy group with the mental group, subjects with a mental disease code scored significantly higher on both non-physical and physical scales of the PFH except for "Planning in Advance" (Scale 9), "Adaptability: People" (Scale 15), "Cooperating with Others" (Scale 25) and "Physical Functioning: Using Senses" (Scale 33) (Table 5 Column 5b). Post-hoc analyses showed significant differences between the mental group and the physical group with regard to all variables, except for four scales "Planning in Advance" (Scale 9), "Acting Rate of Speed" (Scale 11), "Dealing with Conflict Situations" (Scale 24) and "Physical Functioning: Using Senses" (Scale 33) (Table 5 Column 5c). On the physical scales the physical group scored higher compared to the mental group, and on the non-physical scales the mental group scored higher compared to the physical group (Table 5 Column 5c).

Moreover, discriminant analysis showed that the a priori classification of the respondents into three groups (mental, physical, healthy) on the basis of disease codes for $78 \%$ corresponded with the classification on the basis of eleven scale scores obtained from the questionnaire (Table 4c).

Scores of Disease Code Groups Compared to 80th Percentile Values of the Healthy Group The 80th percentile values of the healthy group were compared with the mean scores of the physical and mental groups, distinguished on the basis of disease code. Table 5 (Columns 5a-b) shows the differences between the disease code groups and the 80th percentiles ("C" indicates exceeding of the 80th 
Table 5 Means and standard deviations (SD) per scale and disease code group

\begin{tabular}{|c|c|c|c|c|c|c|c|c|c|c|c|}
\hline \multicolumn{2}{|c|}{ Self-classification scales } & \multirow{2}{*}{\multicolumn{2}{|c|}{$\frac{\text { Healthy }}{1}$}} & \multirow{2}{*}{\multicolumn{2}{|c|}{$\frac{\text { Physical }}{2}$}} & \multirow{2}{*}{\multicolumn{2}{|c|}{$\frac{\text { Mental }}{3}$}} & \multirow{3}{*}{$\begin{array}{l}\text { GLM } \\
4 \\
P<\end{array}$} & \multicolumn{3}{|c|}{ Post-hoc analyses 5} \\
\hline & & & & & & & & & \multirow{2}{*}{$\begin{array}{l}\mathrm{a} \\
\mathrm{Ph}-\mathrm{He}\end{array}$} & \multirow{2}{*}{$\begin{array}{l}\text { b } \\
\mathrm{Me}-\mathrm{He}\end{array}$} & \multirow{2}{*}{$\begin{array}{l}\mathrm{c} \\
\mathrm{Ph}-\mathrm{Me}\end{array}$} \\
\hline & & Mean & SD & Mean & SD & Mean & SD & & & & \\
\hline & Cognitive functioning & & & & & & & & & & \\
\hline 1 & Memory & 20.5 & 9.8 & 22.8 & 14.1 & 38.7 & 19.3 & 0.001 & 0.74 & $0.01 \mathrm{c}$ & 0.01 \\
\hline 2 & Selective attention & 32.6 & 17 & 33.1 & 18.7 & 51.7 & 20.1 & 0.001 & 1.00 & $0.01 \mathrm{c}$ & 0.01 \\
\hline 3 & Sustained attention & 15.2 & 16.5 & 20.7 & 20.7 & 36.9 & 26.6 & 0.001 & 0.06 & $0.01 \mathrm{c}$ & 0.01 \\
\hline 4 & Divided attention & 20.4 & 14.0 & 24.3 & 18.9 & 36.0 & 20.6 & 0.001 & 0.49 & $0.01 \mathrm{c}$ & 0.01 \\
\hline \multirow[t]{2}{*}{5} & Thinking & 19.3 & 13.8 & 26.6 & 17.4 & 41.6 & 19.3 & 0.001 & 0.01 & $0.01 \mathrm{c}$ & 0.01 \\
\hline & Personal functioning & & & & & & & & & & \\
\hline 6 & Underestimating one's own capacity & 28.6 & 14.3 & 25.4 & 14.2 & 38.7 & 19.2 & 0.001 & 0.01 & 0.01 & 0.01 \\
\hline 7 & Overestimating one's own capacity & 19.6 & 12.2 & 20.4 & 12.3 & 26.7 & 14.1 & 0.001 & 1.00 & 0.01 & 0.01 \\
\hline 8 & Acting according to plan & 25.2 & 14.7 & 26.9 & 16.2 & 38.9 & 19.3 & 0.001 & 1.00 & $0.01 \mathrm{c}$ & 0.01 \\
\hline 9 & Planning in advance & 27.9 & 20.6 & 32.6 & 22.8 & 33.9 & 22.9 & 0.088 & 0.14 & 0.32 & 1.00 \\
\hline 10 & Acting autonomously & 17.8 & 12.3 & 17.0 & 13.9 & 25.6 & 16.5 & 0.001 & 0.39 & 0.02 & 0.01 \\
\hline 11 & Acting rate of speed & 12.5 & 15.0 & 24.8 & 22.8 & 27.1 & 23.7 & 0.001 & 0.01 & $0.01 \mathrm{c}$ & 1.00 \\
\hline 12 & Fatigue & 21.6 & 17.8 & 34.2 & 23.5 & 46.8 & 24.7 & 0.001 & 0.01 & $0.01 \mathrm{c}$ & 0.01 \\
\hline 13 & Acting under pressure $\&$ stress & 28.1 & 19.0 & 36.2 & 21.7 & 53.7 & 20.5 & 0.001 & 0.01 & $0.01 \mathrm{c}$ & 0.01 \\
\hline 14 & Adaptability: work & 25.1 & 16.7 & 30.1 & 18.7 & 44.7 & 19.0 & 0.001 & 0.22 & $0.01 \mathrm{c}$ & 0.01 \\
\hline 15 & Adaptability: people & 31.4 & 19.8 & 26.5 & 17.5 & 34.1 & 21.1 & 0.003 & 0.01 & 1.00 & 0.01 \\
\hline 16 & Being assertive & 30.2 & 17.8 & 32.4 & 20.4 & 50.4 & 20.1 & 0.001 & 0.82 & $0.01 \mathrm{c}$ & 0.01 \\
\hline 17 & Motivation & 19.8 & 14.6 & 19.8 & 15.8 & 32.1 & 21.4 & 0.001 & 1.00 & $0.01 \mathrm{c}$ & 0.01 \\
\hline \multirow[t]{2}{*}{18} & Anxious and uncertainty & 22.7 & 15.7 & 22.2 & 16.8 & 42.1 & 20.3 & 0.001 & 1.00 & $0.01 \mathrm{c}$ & 0.01 \\
\hline & Social functioning & & & & & & & & & & \\
\hline 19 & Informing other subjects & 22.1 & 15.7 & 25.3 & 16.5 & 34.5 & 18.8 & 0.001 & 0.67 & 0.01 & 0.01 \\
\hline 20 & Dealing with emotional problems of other subjects & 29.3 & 13.9 & 28.7 & 14.3 & 38.7 & 15.0 & 0.001 & 1.00 & 0.01 & 0.01 \\
\hline 21 & Expressing own feelings & 29.5 & 16.6 & 35.6 & 17.0 & 48.3 & 18.7 & 0.001 & 0.01 & $0.01 \mathrm{c}$ & 0.01 \\
\hline 22 & Controlling own emotions & 25.8 & 16.1 & 27.7 & 16.4 & 46.9 & 19.2 & 0.001 & 1.00 & $0.01 \mathrm{c}$ & 0.01 \\
\hline 23 & Dealing with inner conflicts & 47.0 & 19.1 & 44.3 & 17.8 & 58.8 & 20.4 & 0.001 & 0.85 & 0.01 & 0.01 \\
\hline 24 & Dealing with conflict situations & 40.1 & 18.5 & 46.8 & 18.3 & 47.9 & 18.1 & 0.001 & 0.01 & 0.01 & 1.00 \\
\hline 25 & Cooperating with others & 17.5 & 15.6 & 14.1 & 15.3 & 19.7 & 17.5 & 0.003 & 0.01 & 1.00 & 0.02 \\
\hline 26 & Contact with other subjects & 29.8 & 21.2 & 32.8 & 21.0 & 42.9 & 23.3 & 0.001 & 0.71 & 0.01 & 0.01 \\
\hline 27 & Pleasure & 16.8 & 15.2 & 20.7 & 17.8 & 37.9 & 24.2 & 0.001 & 1.00 & $0.01 \mathrm{c}$ & 0.01 \\
\hline 28 & Dealing with setbacks & 27.4 & 16.4 & 31.6 & 17.4 & 47.0 & 18.1 & 0.001 & 0.06 & $0.01 \mathrm{c}$ & 0.01 \\
\hline \multirow[t]{2}{*}{29} & Social support & 22.1 & 21.2 & 22.5 & 22.2 & 31.0 & 24.2 & 0.002 & 1.00 & 0.01 & 0.01 \\
\hline & Physical functioning & & & & & & & & & & \\
\hline 30 & Using back/legs & 5.9 & 9.1 & 34.8 & 23.9 & 15.1 & 18.7 & 0.001 & $0.01 \mathrm{c}$ & $0.01 \mathrm{c}$ & 0.01 \\
\hline 31 & Using hands/arms & 4.5 & 9.1 & 29.0 & 26.8 & 14.3 & 18.3 & 0.001 & $0.01 \mathrm{c}$ & $0.01 \mathrm{c}$ & 0.01 \\
\hline 32 & Using neck & 3.9 & 10.3 & 22.9 & 26.2 & 14.3 & 24.0 & 0.001 & $0.01 \mathrm{c}$ & $0.01 \mathrm{c}$ & 0.01 \\
\hline 33 & Using senses & 5.0 & 10.1 & 11.9 & 15.7 & 11.0 & 14.7 & 0.001 & 0.01 & 0.07 & 0.94 \\
\hline
\end{tabular}

He healthy, $P h$ physical, $M e$ mental groups)

$P \leq$ (column 4) based on ANOVA with correction for age and sex; $P \leq$ (column 5 ) based on Scheffé criterion; c = exceeding the 80th percentile

percentile value). Figure 3 illustrates the mean scores of all groups and the 80th percentile value of all 33 scales, based on classification by disease codes. Compared with the 80th percentile values of the healthy group, the mean scores of the physical group exceeded the 80th percentile values of the physical scales except for the scale "Physical Functioning: Using Senses" (Scale 33) (Table 5 Column 5a). They did not exceed the 80th percentile values of the nonphysical scales. The mean scores of the mental group were higher than the 80th percentile values of the healthy group 


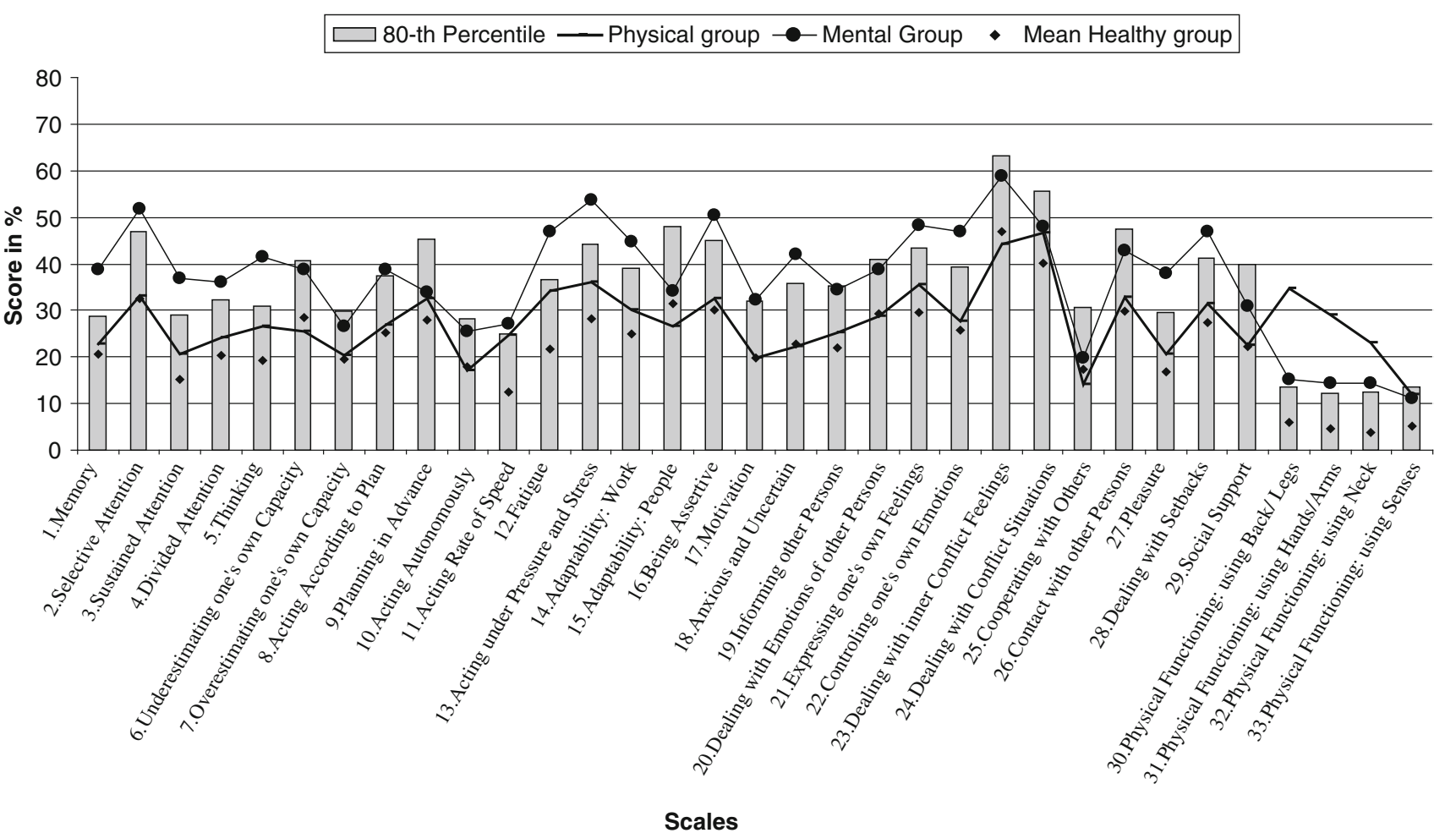

Fig. 3 Mean scale scores of healthy, physical and mental groups formed on the basis of disease code. Per scale the 80th percentile value (bars) of the healthy group

on 17 non-physical scales and three physical scales (Table 5 Column 5b).

Representation of Specific Disease Codes in the Questionnaire Scores In addition, to examine whether types of limitations expressed in a specific disease code were clearly reflected in the scores of the related scales, four groups of subjects were composed based on disease codes: back disorders $(n=32)$, problems using hand/arm/shoulder/neck $(n=35)$, reactive disorders (tension complaints, mourning reaction, burn out, overwork) $(n=79)$ and endogenous disorders (anxiety disorders, adjustment disorders, mood disorders, non-organic psychosis) $(n=18)$. Their PFH scores were compared to the 80th percentile value (Fig. 4). The back disorders group scored the highest on the scale "Physical Functioning: Back/Legs" (Scale 30) and exceeded the 80th percentile values of the scales "Physical Functioning: Back/Legs" (Scale 30), "Physical Functioning: Using Hands/Arms" (Scale 31) and "Physical Functioning: Using Neck" (Scale 32). The group with problems using hand/arm/shoulder/neck scored the highest on the scale "Physical Functioning: Using Hands/Arms" (Scale 31) and exceeded the 80th percentile values of the scales "Physical Functioning: Using Back/Legs" (Scale 30), "Physical Functioning: Using Hands/Arms" (Scale 31) and "Physical Functioning: Using Neck" (Scale 32).
The reactive disorders group and endogenous disorders group exceeded the 80th percentile values on 15 of the 23 non-physical scales, respectively.

\section{Discussion}

The aim of this study was to evaluate the reliability and validity of the PFH. Based on the results, the reliability of the PFH, defined in this study as internal consistency and test-retest reliability, is in general sufficient to good. The validity of the questionnaire is encouraging. From the results it can be concluded that the questionnaire discriminates between persons with physical and mental limitations on the expected scales, and between the limitation groups and the "healthy" group. This applies for grouping on the basis of self-classification as well as disease codes. The mixed group can be distinguished from the healthy and physical groups on both the physical and mental scales of the PFH, and from the mental group on only the physical scales. Furthermore, limitations due to specific types of complaint (low back pain, fatigue, concentration problems) or diagnosed disorders (musculoskeletal disorders, reactive disorders, endogenous disorders) are clearly reflected in the scores of the related subscales of the PFH. 


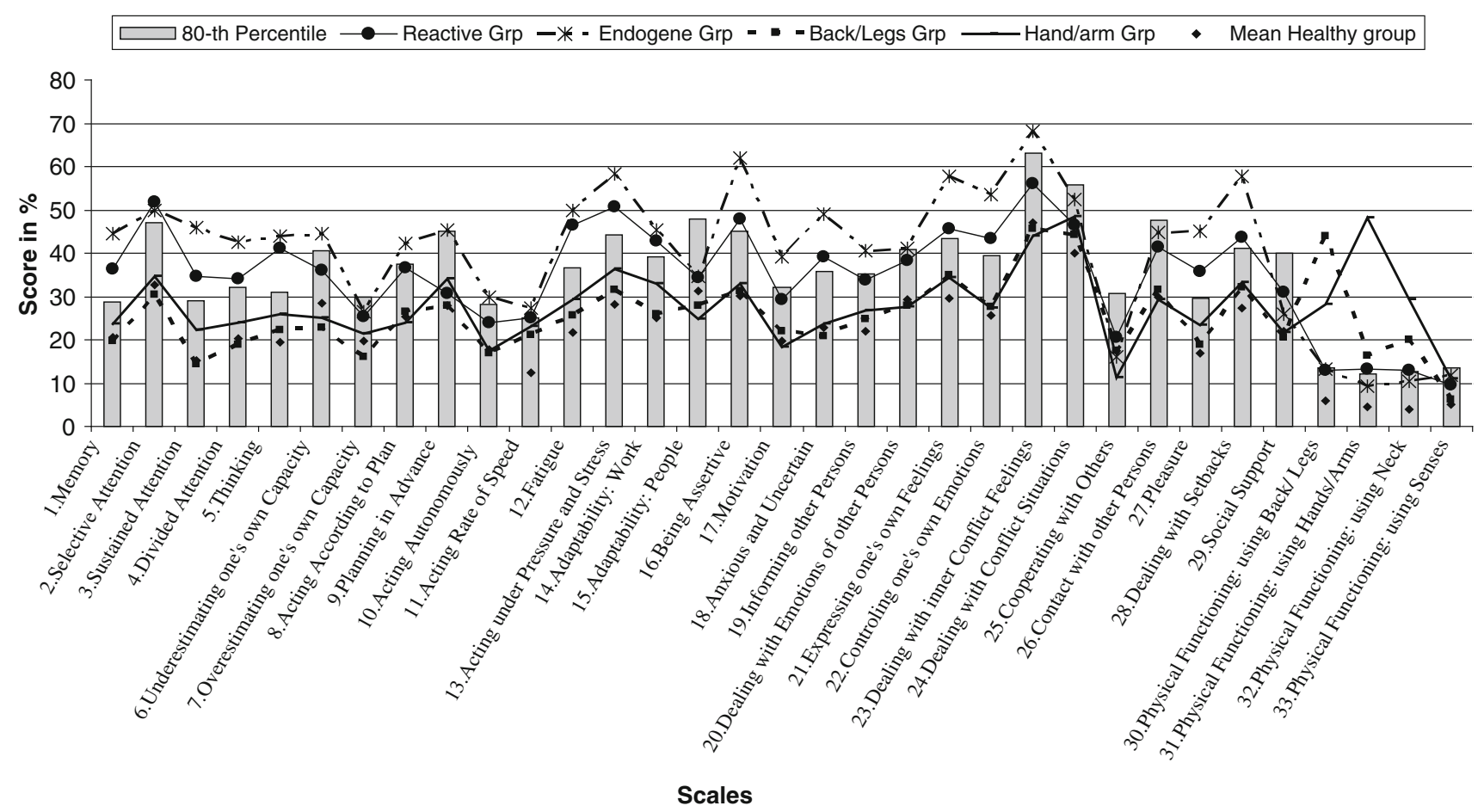

Fig. 4 Mean scale scores of healthy group contrasted with groups with Hand/Arm, Back/Legs, Endogenous or Reactive complaints formed on the basis of disease code. Per scale the 80th percentile value (bars) of the healthy group

No gold standard exists for measuring work disabilities and functional limitations. In this study an a priori classification of the respondents has taken place for validation purposes on the basis of their own statements (self-classification) and on the basis of the disease codes assigned by physicians. Self-classification and classification on the basis of disease codes results in the same classification for $75 \%$ of the respondents in the physical, mental and mixed groups, for $66 \%$ of the respondents in the mental and mixed groups, for $90 \%$ in the physical and mixed groups, and for $96 \%$ in the physical and mental groups. It would thus seem that the perceived limitations indicated by the client to a large extent predict the outcome of the examination conducted by insurance physicians and occupational health physicians as is indicated in other studies [1, 2, 4, 5]. Selfclassification has been chosen as the main validation criterion, while the questionnaire may also be useful as an inventory of the limitations perceived by the client who submits an application to the insurance or occupational health physician. The client should at least be able to recognize in the scale scores those limitations that he/she has indicated. On the basis of these analyses, there is a significant relationship between the questionnaire scores and self-classification. The specific limitations indicated by the respondent are expressed in the limitation scores on the related scales of the PFH questionnaire. In addition, differentiation only between the physical and mental groups, without a mixed form, shows that the scores on the physical scales differentiate between persons with and without physical limitations as might be expected. Additionally, the group with only mental limitations can generally be distinguished from the groups without such limitations (healthy group and group with physical limitations) on the basis of the mental scale scores. The distinction between the healthy group and the limitation groups on the basis of the appropriate scale scores fits expectations significantly better when the critical values (80th percentile of the healthy group) are used. By making the size of this critical value stricter, thereby taking into account separate subgroups (men/women, age classes, working/nonworking), the diagnosticity and sensitivity of the questionnaire might be improved [29]. However, to establish the severity of the limitations it might be necessary to use other types of criterion other than the currently used statistical standards. For example, scale scores ought to be obtained from subjects with specific diseases whose limitations have already been investigated and recognized. Further differentiation between limitations due to the different causes for these limitations is needed and norm groups for specific limitation groups should be established. Moreover, validation of the PFH with other, more specific and previously validated instruments (e.g., attention and memory tests, autonomy scale, depression scale) may be of interest. In the present study we were not able to collect other competing measurements of limitations in work functioning. In future research, this kind of concurrent validity for the $\mathrm{PFH}$ 
should be investigated by comparing the results of the PFH measurements with other both physical and mental measurements which focus on one domain of functioning.

The PFH was developed as a measurement for gathering self-reported information from the client about that client's limitations in functioning. This information can be helpful for the physician who has to examine the client with respect to all the limitations that are listed in the FAL. The PFH has to be used in conjunction with the FAL. Each of the 33 scales refers to specific items in the FAL. However, further research may be necessary to determine whether the 33 conceptually distinct aspects of physical and mental limitations in work functioning can be distinguished. Such a study should be based on "accepted" claims for a disability pension. The minimum number of distinct aspects of physical and mental limitations can be determined by describing all the physical and mental limitations in work functioning. A subsequent research study might examine the extent to which these distinct aspects that are derived from the accepted claims can also be distinguished on the basis of self-reports.

The PFH may be useful as a type of "Injury Claim Form" in which the client him/herself can register the limitations which he or she experiences in daily functioning. What are the advantages and disadvantages of using such a form within the context of occupational and insurance medicine? The questionnaire may facilitate the systematic acquisition of information needed for claim appraisal, similar to the injury declaration form which is used by insurance companies. It can be used as a first step in the process of screening and classification required for assessment of work (dis)ability and medical insurance claims. The $\mathrm{PFH}$ asks the insured person for certain information in a standardized manner, which makes the information more easily accessible to the physician. The physician can then use this information to conduct a more focused assessment interview and can possibly make other strategic decisions in advance. The results can also be a reason to refer the client for more specialized support in terms of diagnosis and appraisal. In addition to these benefits for efficiency, the quality of the diagnostic process can benefit in various ways from the use of a self-report questionnaire. Discrepancy between self-classification and disease code encourages a critical review of the medical decision and can reduce a number of the undesirable biases that may occur in the judgment. From research, it appears that labor experts make extensive use of routines and heuristics that lead to tunnel vision, blind spots and biases in the assessment of clients [30]. By compelling someone to justify or to substantiate his/her decision, the influence of biases in the assessment process is decreased [31, 32]. The application of a questionnaire that gives concurrent information with respect to a broad spectrum of possible limitations will keep the professional alert to all of these limitations. And, last but not least, it has been shown that insured people are satisfied with this questionnaire approach because it makes them feel they are being heard; in addition, they are more satisfied with the outcome of the claim appraisal [33].

A number of disadvantages must also be taken into consideration concerning the use of questionnaires. It is known that self-appraisal can differ from that of an expert and/or from other people's appraisals. From a comparison between the results of the mental limitations list (PBL), filled in by insurance physicians, and the subjective mental limitation list (SPBL), filled in by the insured themselves, over-reporting of limitations by the insured clients was found [34]. In addition, Brouwer et al. [35] found overreporting of limitations in patients with chronic low-back pain when the self-report, clinical examination and functional test results were compared. The use of reference data derived from persons with "accepted" claims will also suffer from similar over-reporting of limitations. Consequently, comparison of individual data with such reference data should correct this bias automatically to some extent. It is known that correct assessment, particularly in claim appraisal situations, is complicated because it is partly a situation where two parties are negotiating. The insured person has a personal interest in a specific outcome of the appraisal process. The influence of answer tendencies on scoring behavior cannot be excluded. However, such answer tendencies or biases can be detected by using catchtrials and tendency-sensitive items. Moreover, the physician may prove the consistency of the information obtained from the questionnaire with information from other sources.

In conclusion, the reliability and validity of the $\mathrm{PFH}$ were found to be satisfactory. The PFH is able to discriminate between groups with expected differences in type of functional limitations. The PFH would appear to be an appropriate instrument for measuring functional limitations in subjects on sick leave and in those who are receiving disability pension and can be a starting point in a systematic disability claim procedure. The PFH enables the client to present in a standard and systematic way his/her limitations in functioning. By using this questionnaire the insurance and occupational health physician can gather information about the functional limitations of the client prior to the assessment interview. Further differentiation between type of limitations to establish the meaningfulness of these scales will demand further research effort. Especially as concerns validation, steps will have to be taken to establish norms for specific groups. The relationship between individual scale scores and functional limitations established in another way by accepted claims for disability pension should be kept in mind. The results of the discriminant analyses show that there may be opportunities to 
shorten the questionnaire substantially without any decline in the current psychometric properties.

Acknowledgments We would like to thank the Arbo Unie Drenthe (Emmen office) and Arbo Unie Midden Nederland (Utrecht office) for their help in obtaining respondents, and Ms C. Bonneau for her administrative and translation support.

Open Access This article is distributed under the terms of the Creative Commons Attribution Noncommercial License which permits any noncommercial use, distribution, and reproduction in any medium, provided the original author(s) and source are credited.

\section{References}

1. de Bont AA, Berendsen L, Boonk MPA, van den Brink JC. In de spreekkamer van de verzekeringsarts. Een etnografisch onderzoek naar de WAO claimbeoordeling [In the consulting room of the insurance physician. An ethnographic study of the assessment for disability pensions.] Zoetermeer, the Netherlands: CTSV; 2000.

2. Visser M. Psychische beperkingen en de WAO. [Mental limitations and Work Disability Pension.] Maastricht: Faculty of Health Sciences; 2001.

3. Landelijk Instituut voor Sociale Verzekeringen (LISV). Claim Beoordelings- en Borgingssysteem (CBBS). [The Claim Assessment and Assurance System]. Amsterdam: LISV; 2002.

4. Mul CAM, Verkleij HEM, Hazelett AM, de Roos F. Kwaliteit van de oordeelsvorming. [Quality of assessment.] Hoofddorp: TNO; 1999.

5. Spanjer J, Krol B, Popping R, Groothoff JW, Brouwer S. Disability assessment interview: the role of detailed information on functioning in addition to medical history-taking. J Rehabil Med. 2009;41:267-72.

6. Krause N, Frank JW, Dasinger LK, Sullivan TJ, Sinclair SJ. Determinants of duration of disability and return-to-work after work-related injury and illness: challenges for future research. Am J Ind Med. 2001;40:464-84.

7. Tuomi K, Ilmarinen J, Eskelinen L, Jarvinen E, Toikannen J, Klockars M. Prevalence and incidence rates of disease and work ability in different work categories of municipal occupations. Scand J Work Environ Health. 1991;17(Suppl 1):67-74.

8. Abdel-Moty E, Fishbain DA, Khalil TM, Sadek S, Cutler R, Steele-Rosomoff R, et al. Functional capacity and residual functional capacity and their utility in measuring work capacity. Clin J Pain. 1993;9:168-73.

9. Bot SDM, Terwee CB, van der Windt DAWM, Bouter LM, Dekker J, de Vet HCW. Clinimetric evaluation of shoulder disability questionnaires: a systematic review of the literature. Ann Rheum Dis. 2004;63:335-41.

10. Grotle M, Brox JI, Vollestad NK. Functional status and disability questionnaires: what do they assess? A systematic review of back-specific outcome questionnaires. Spine. 2005;30:130-40.

11. Wind $\mathrm{H}$, Gouttebarge V, Kuijer PPFM, Frings-Dresen MH. Assessment of functional capacity of the musculoskeletal system in the context of work, daily living, and sport: a systematic review. J Occup Rehabil. 2005;15:253-72.

12. Matheson L, Mayer J, Mooney V, Sarkir A, Dreisinger T, Verna $\mathrm{J}$, et al. A method to provide a more efficient and reliable measure of self-report physical work capacity for patients with spinal pain. J Occup Rehabil. 2008;18:46-57.

13. Millard RW. A critical review of questionnaires for assessing pain-related disability. J Occup Rehabil. 1991;1:289-302.

14. Fries J, Spitz PW, Young DY. The dimensions of health outcomes: the health assessment questionnaire, disability and pain scales. J Rheumatol. 1982;9:789-93.
15. Verkuilen ML, Schellekens JMH, Mulders HPG, Bakker PJJ. Vragenlijst Ervaren Functioneren en Gezondheid (EFG): clientbeleving van functionele mogelijkheden. [Perceived Functioning and Health questionnaire: client's perception of their functional capacity]. University of Groningen: Master Thesis; 2002.

16. U.S. Department of Labor, Employment and Training Administration. Dictionary of occupational titles. 4th ed. Washington: USGPO; 1977.

17. van Veldhoven M, de Jonge J, Broersen S, Kompier M, Meijman TF. Specific relationships between psychosocial job conditions and job-related stress: a three-level analytic approach. Work Stress. 2002;16:207-28.

18. Karasek RA, Theorell T. Healthy work: stress, productivity, and the reconstruction of working life. New York: Basic Books; 1990.

19. de Jonge J, Schaufeli WB. Job characteristics and employee wellbeing: a test of Warr's Vitamin Model in health care workers using structural equation modelling. J Organ Behav. 1998;19: 387-407.

20. Koslowsky M. Modeling the stress-strain relationship in work settings. London: Routledge; 1998.

21. Elovainio M, Kivimäki M, Steen N, Kalliomäki-Levanto T. Organizational and individual factors affecting mental health and job satisfaction: A multilevel analysis of job control and personality. J Occup Health Psychol. 2000;5:269-77.

22. CAS: classificaties voor Arbo en SV. Classificatie van klachten, ziekten en oorzaken voor bedrijfs- en verzekeringsartsen. [CAS: Classification of symptoms, diseases and causes for occupational and insurance physicians]. Amsterdam: Dutch Institute for Social Insurance, UWV; 2002.

23. World Health Organization. Manual of the international statistical classification of diseases, injuries, and causes of death. Geneva: World Health Organization; 1977.

24. Cronbach LJ. Essentials of psychological testing. New York: Harper \& Row; 1990.

25. Nunnally JC, Bernstein IH. Psychometric theory. 3rd ed. New York: McGraw-Hill; 1994. p. 264-5.

26. Evers A, van Vliet JC, Groot CJ. Documentatie van tests en testresearch in Nederland. [Documentation of tests and test research in the Netherlands.]. Assen: van Gorcum; 2000. p. 1411.

27. Manly BFJ. Multivariate statistical methods. 3rd ed. Boca Raton: Chapman \& Hall/CRC; 2005.

28. Norušis MJ. SPSS 14.0 guide to data analysis. Upper Saddle River: Prentice Hall; 2006.

29. Lezak MD, Howieson DB, Loring DW, Hannay HJ. Neuropsychological assessment. 4th ed. Oxford: University Press; 2004.

30. Bergsma EN, Mul CAM, Mullenders P, Berendsen L, van Beek IGA. Geschikt of ongeschikt. De rol van arbeidsdeskundigen bij de WAO-beoordeling. [Disabled or not disabled for work. The role of the labor expert in the assessment of work disability insurance claims.] Den Haag, Inspectie Werk en Inkomen; 2002.

31. Dijksterhuis A, van Knippenberg A, Kruglanski AW, Schaper C. Motivated social cognition: need for closure effects on memory and judgment. J Exp Soc Psychol. 1996;32:254-70.

32. Webster DM, Richter L, Kruglanski AR. On leaping to conclusions when feeling tired: mental fatigue effects on impressional primacy. J Exp Soc Psychol. 1996;32:181-95.

33. Bakker PJ. Vragenlijst ervaren functioneren en gezondheid als schadelastformulier. [Questionnaire Perceived Functioning and Health as an Injury Claim Form]. Utrecht: NSOH; 2003.

34. Jordan K, Ong BN. Researching limiting long-term illness. Soc Sci Med. 2000;50:397-405.

35. Brouwer S, Dijkstra PU, Stewart RE, Goeken LN, Groothoff JW, Geertzen JH. Comparing self-report, clinical examination and functional testing in the assessment of work-related limitations in patients with chronic low back pain. Disabil Rehabil. 2005;27: 999-1005. 